\title{
The fire at Long Grove Hospital
}

\section{History in flames}

\author{
Henry R. Rollin
}

In 1993, Long Grove Hospital, Epsom, Surrey, in pursuance of the Government's relentless policy of translocating patients suffering from mental disorder from mental hospitals to the community, closed its doors. On the night of $22 / 23$ September the Great Hall* of the hospital, a superb example of late Victorian-Gothic architecture in the grand style, was gutted by fire. The presumption is that the fire was either a deliberate act of arson, or that it was accidentally caused by vagrants who have taken up residence in the deserted buildings. But however started, the inferno, literally and symbolically, brought to a tragic and inglorious end a hospital with a long and proud tradition of excellence.

It is a grim irony that Long Grove owed its existence indirectly to another fire described by Hunter \& Macalpine (1974) as "the worst ever disaster in English asylum history". In the

-This assembly hall was known, as were others in the mental hospitals of the period, as the Recreation Hall, although it was also used to house large meetings of staff or of learned societies. morning of 27 January 1903, 52 female patients perished in a fire in temporary wards at Colney Hatch Lunatic Asylum in North London (later Friern Hospital) (Rollin, 1989).

It was imperative that, in order to assuage public anxiety and to meet the additional need for beds occasioned by the fire, the London County Council had to build further hospitals. In something of a rush, work began on Long Grove in 1903 based on the designs of G. T. Hines, a noted institutional architect, originally used for Bexley Hospital, Kent. (The same plans were used for Horton Hospital, opened in 1902). With the aid of a specially built light railway the work was completed and the hospital opened the same year in 1907. Such was the demand for accommodation that the hospital filled at an alarming rate. Thus, in the Report of the Commissioners in Lunacy, dated 11 March 1911, the patient population is given as 2,$127 ; 1,121$ males and 1,006 females. The hospital was regarded as a showpiece and apparently regarded as such by the Commissioners who reported, inter alia, "The wards, dormitories and all parts of the building

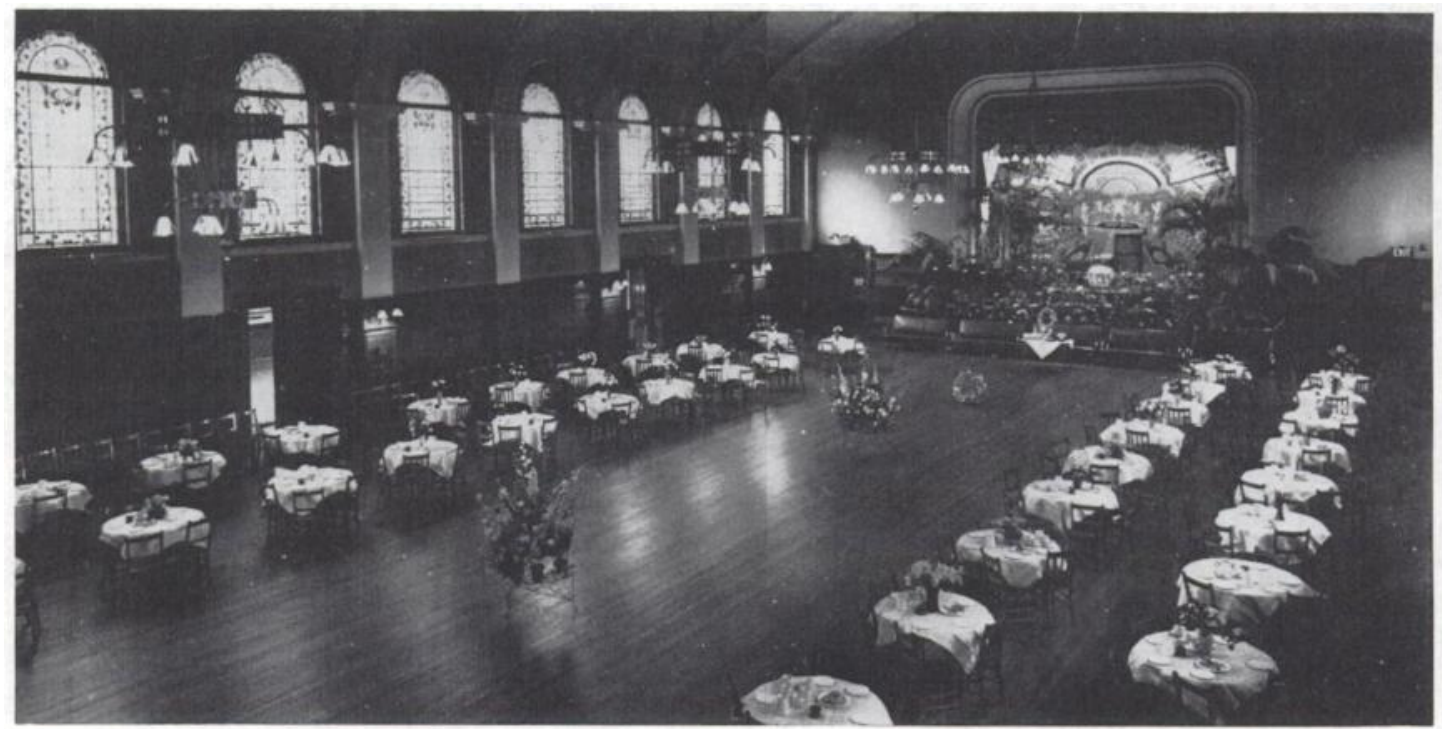

Fig. 1. The Great Hall, Long Grove Hospital. 
were in excellent order, and there is a good supply of books, and of flowers, birds and objects of various kinds to brighten the rooms and interest their inmates". The grounds, including a collection of rare trees, were, and until the final curtain, continued to be, exceptionally well maintained.

Long Grove has always boasted an excellent medical staff. Over the years it has included, for example, Bernard Hart, author of the classic, The Psychology of Insanity, and Edward Mapother who was to be translated to the Maudsley Hospital and later to become the first Professor of Psychiatry in the University of London and the first full-time professor of psychiatry in England.

Worthy of special mention are two medical men who have headed the hospital. The first medical superintendent was (Sir) Hubert Bond, later to become Senior Medical Commissioner of the Board of Control and, in 1921, President of the Medico-Psychological Association. The second is A. B. Monro who served as the last physician superintendent from 1951 until he retired in 1973. Monro was distinguished as an innovative psychiatrist, particularly in the fields of industrial therapy and adolescent psychiatry. But he will best be remembered for his outstanding services to the Royal Medico-Psychological Association (RMPA). In 1957 he was appointed
General Secretary and as such he played a vital part in preparing the ground for, and taking part in, the prolonged and delicate negotiations with the Privy Council leading to the foundation of the Royal College in 1971 (Howells, 1991). He served as the College's first registrar in 1971 and in 1973 , as an acknowledgement of his services, he was elected to the honorary fellowship.

This thumb-nail sketch of the history of an outstanding hospital and its staff serves to underline the tragedy of its closure. The destruction of its Great Hall, the symbolic heart of the hospital, is an indictment of those responsible for the wanton disregard paid to the security of an historic building.

\section{References}

HowelLS. J. (1991) The establishment of the Royal College of Psychiatrists. In 150 Years of Brttish Psychiatry 1841 1991. eds (G. E. Berrios and H. Freeman) London: Gaskell (Royal College of Psychiatrists).

Hunter, R. \& MACALPINE, I. (1974) Psychiatry for the Poor. p. 49, London: Dawsons of Pall Mall.

Rollin, H. R. (1989) The fire at Colney Hatch Lunatic Asylum, 1903, remembered. Psychiatric Bulletin, 13, 188-189.

Henry R. Rollin, Emeritus Consultant, Horton Hospital, Surrey

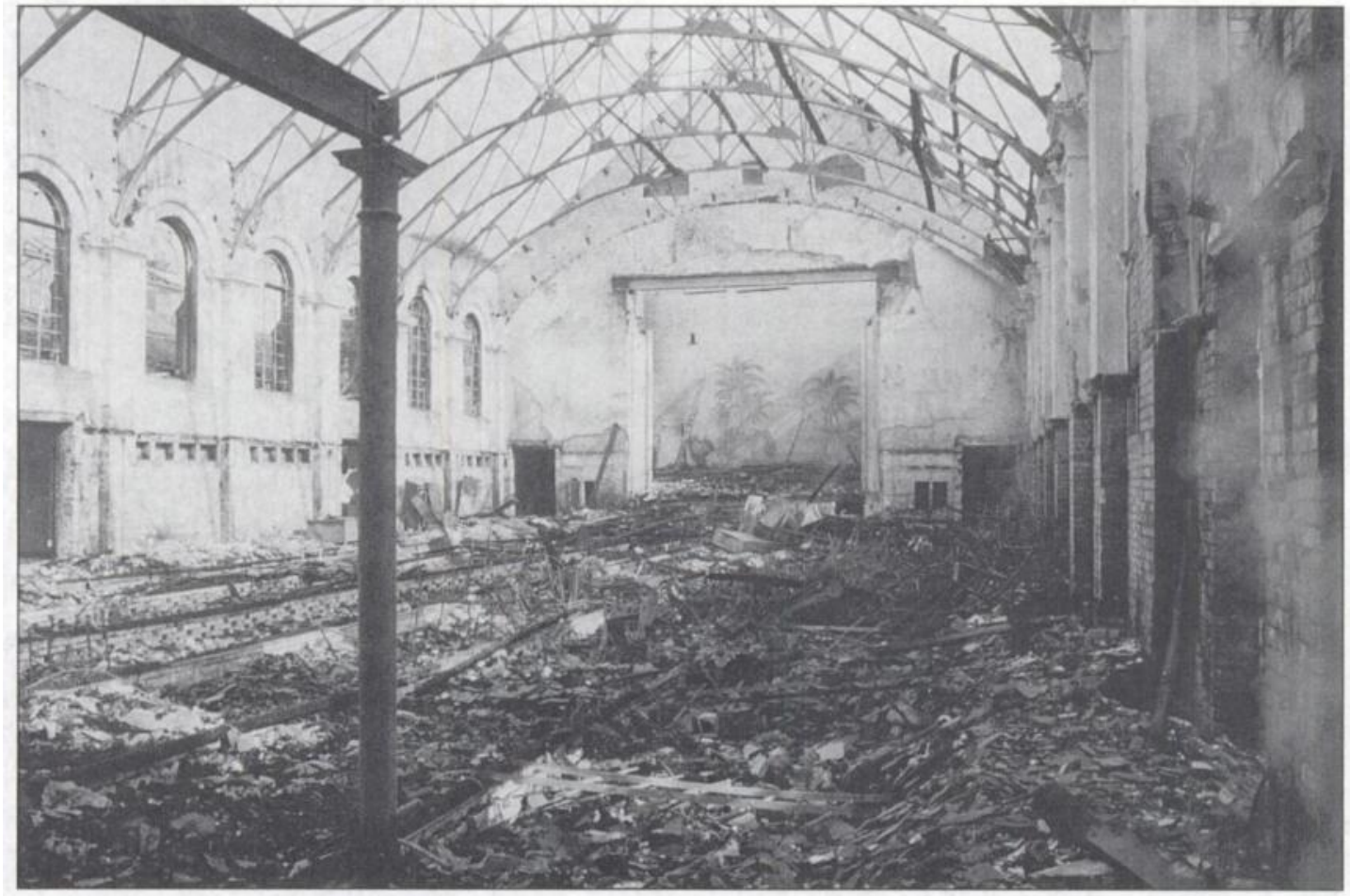

Fig. 2. After the fire. (Courtesy of Mike Drewett, Surrey Fire and Rescue Service). 